\title{
Validation of the Pain Beliefs and Perceptions Inventory
}

\author{
Samuel F Mikail PhD, Joyce L D’Eon PhD, Théo A De Gagné MA
}

\section{SF Mikail, JL D'Eon, TA De Gagné. \\ Validation of the Pain Beliefs and Perceptions Inventory. Pain Res Manage 1996;1(1):31-38.}

OBJECTIVE: To examine the test-retest reliability, construct validity and factor structure of the Pain Beliefs and Perceptions Inventory (PBPI).

DESIGN: A sample of 195 individuals attending a chronic pain clinic completed the PBPI along with a preclinic assessment battery. A subset of this sample completed the assessment package two to four weeks and four to six months later in order to examine the test-retest reliability of the PBPI.

RESULTS: Confirmatory factor analysis revealed a four-factor solution: pain constancy, self-blame, mystery and understanding of chronicity. Internal consistency estimates ranged from 0.63 to 0.75 . Pain constancy and understanding of chronicity had good testretest reliability, while test-retest reliability of the remaining subscales was not adequate. These results differ from those reported in the initial development of the PBPI. Construct validity was determined through examination of correlations between the PBPI and the Beck Depression Inventory, the McGill Pain Questionnaire, the Multidimensional Pain Inventory and a self-blame questionnaire.

CONCLUSIONS: The results of this investigation are consistent with the findings of recent investigations that revealed a four-factor solution to the PBPI. However, the subscales of this instrument were not found to be uniformly stable over time. These results suggest that further examination and refinement of item content for two of the subscales are required before the instrument is suitable for clinical use.

Key Words: Chronic pain, Confirmatory factor analysis, Pain Beliefs and Perceptions Inventory, Psychometric properties

\section{Validation de l'Inventaire des perceptions et des croyances sur la douleur}

OBJECTIF : Examiner la fiabilité de test-retest, la validité de conception et la structure factorielle de l'Inventaire des perceptions et des croyances sur la douleur (IPCD).

MODÈLE : Un échantillon de 195 individus fréquentant une clinique de la douleur chronique a complété l'IPCD de même qu'une batterie de tests précliniques. Un sous-groupe de cet échantillon a complété la série d'évaluations deux à quatre semaines et quatre à six mois plus tard de façon à évaluer la fiabilité de test-retest de l'IPCD.

RÉSULTATS : L'analyse factorielle confirmative a révélé une solution quadrifactorielle : la constance de la douleur, l'autoculpabilité, le mystère et la compréhension de la chronicité. Les valeurs estimées de la cohérence interne allaient de 0,63 à 0,75 . La constance de la douleur et la compréhension de la chronicité démontraient une bonne fiabilité de test-retest, tandis que la fiabilité de test-retest des sous-échelles restantes n'était pas adéquate. Ces résultats diffèrent de ceux rapportés au cours de la conception initiale de 1'IPCD. La validité de conception a été déterminée par le biais de l'examen des corrélations entre l'IPCD et l'Inventaire de Beck sur la dépression (Beck Depression Inventory), le Questionnaire McGill sur la douleur (McGill Pain Questionnaire), l'Inventaire multidimensionnel sur la douleur et un questionnaire d'autoculpabilité.

CONCLUSIONS : Les résultats de cette recherche corroborent avec ceux de recherches récentes qui ont révélé une solution quadrifactorielle à l'IPCD. Cependant, les sous-échelles de cet instrument ne se sont pas révélées uniformément stables dans le temps. Ces résultats font croire qu'il faut analyser avec plus de profondeur et raffiner le contenu des items de deux des sous-échelles avant que cet instrument puisse être utilisé en situation clinique.

Department of Psychology, The Rehabilitation Centre; and School of Psychology, University of Ottawa, Ottawa, Ontario

Correspondence: Dr Samuel F Mikail, Department of Psychology, The Rehabilitation Centre, Ottawa, Ontario K1H 8M2. Telephone 613-737-7350 ext 5565, fax 613-737-7056, e-mail smikail@rohcg.on.ca

Received for publication June 1, 1995. Accepted September 29, 1995 
A number of investigators have suggested that patients' beliefs and expectancies are important mediators of the chronic pain experience $(1,2)$. Williams and Thorn (1) define pain beliefs as "a subset of a patient's belief system which represents a personal understanding of the pain experience". Several investigations have demonstrated a significant association between patients' beliefs about their pain and various aspects of emotional adjustment, disability status and responsiveness to treatment (3). For example, Jensen and Karoly (4) found that patients' beliefs regarding their ability to control pain were positively related to psychological adjustment. Furthermore, these authors found that beliefs regarding control over pain interacted with pain intensity in predicting activity levels. In a subsequent study, Jensen and Karoly (5) reported that patients' beliefs regarding their extent of disability were negatively correlated with activity level and psychological well-being, and positively related to health care utilization. Most recently, Jensen et al (6) demonstrated that several dimensions of pain beliefs are correlated with level of psychosocial dysfunction, degree of physical disability and number of pain-related emergency room visits. These results suggest that the various dimensions of pain beliefs are differentially related to several elements of patients' physical and psychological functioning. Williams and Thorn (1) provide preliminary evidence that pain beliefs may also be related to treatment compliance and outcome. Collectively, these findings underline the importance of accurately assessing pain beliefs of chronic pain patients.

Currently, several measures of pain beliefs exist. This investigation examined the psychometric properties of one measure of this construct, the Pain Beliefs and Perceptions Inventory (PBPI), developed by Williams and Thorn (1). The PBPI is a self-report measure in which subjects are asked to rate their degree of agreement with each of 16 statements using a four-point Likert scale with no zero point. Factorial validity was determined using principal axis factoring with orthogonal rotation (1), yielding three subscales: beliefs about the stability of one's pain (TIME), the extent to which individuals view their pain as mysterious and unexplained (MYST) and the extent to which individuals blame themselves for their pain - self-blame (S-B). Three recent investigations examining the factor structure of the PBPI (7-9) reported a four-factor solution. In these studies, the TIME subscale emerged as two separate factors: acceptance (or pain permanence [9]) and constancy. These studies employed principal component analysis with orthogonal rotation, although Morley and Wilkinson (9) followed this with an oblique rotation using the Oblimin procedure. One of the aims of the present investigation was to determine the factor structure of the PBPI using confirmatory factor analyses (CFA), while examining the degree of correlation among the factors. Factors were allowed to correlate based on Gorsuch's (10) conclusion that use of uncorrelated factors in clinical research is generally unjustified.

Williams and Thorn (1) provided evidence for the construct validity of the three subscales by examining their correlations with a number of criterion measures. The TIME subscale was highly correlated with subjective pain intensity. This result is consistent with laboratory investigations that have demonstrated a strong correlation between subjective pain ratings and subjects' level of awareness of the likely duration of pain. One limitation of this methodology was the use of a nonstandardized, global rating of pain severity. In the present study two standardized measures of pain severity were used: the McGill Pain Questionnaire (MPQ [11]) and the pain severity subscale of the Multidimensional Pain Inventory (MPI [12]). The global rating of pain severity used in the original study (1) was also included.

Williams and Thorn (1) found that scores on the MYST subscale were associated with poor treatment compliance, particularly with physiotherapy. Compliance ratings were used as an indirect measure of activity level. The authors argued that individuals who view pain as mysterious lack a framework for understanding increased pain intensity and muscle soreness associated with increases in activity. Although this logic is sound, the relationship was identified post hoc. A potential strength of this methodology was the use of an observational measure of activity, which may provide a more objective indication of activity levels. The present investigation modified this methodology by examining the relationship between self-reported activity levels and MYST scores. The general activity subscale of the MPI (12), which is a well-established and standardized multidimensional measure, served as the criterion measure.

Williams and Thorn (1) demonstrated the construct validity of the S-B subscale by examining the relationship among selfblame, depression, locus of control, and the Bulman and Wortman measure of self-blame (13). The strongest association was found between the S-B subscale and Bulman and Wortman's measure. This measure is a four-item scale for which no psychometric properties have been reported. Thus, correlations between these two scales must be interpreted cautiously. In the present study an established measure of self-blame (14) was used, in addition to the Bulman-Wortman scale.

A final aim of the study was to examine the temporal stability of the PBPI. Morley and Wilkinson (9) noted a number of concerns regarding the construct validity of the PBPI and felt that these may be due, in part, to instability of scores. Thus, they suggested that this aspect of the PBPI required further attention.

In summary, the present investigation examined the factorial validity of the PBPI using a heterogeneous chronic pain sample. The construct validity of the PBPI was further examined by exploring the pattern of correlations between the subscales of the PBPI and several standardized measures, thereby extending the methodology of Williams and Thorn (1). Finally, test-retest reliability of the PBPI was determined.

\section{Sample and procedure}

\section{SUBJECTS AND METHODS}

A letter describing the nature and purpose of the study was mailed to patients referred to The Rehabilitation Centre's pain clinic before their appointment. Accompanying the letter was a questionnaire package which included the PBPI, a demographics form, the Mittelstaedt Blame Questionnaire (MBQ [14]) and a standardized preclinic assessment battery $(15,16)$. This battery consisted of the Beck Depression Inventory (BDI [17]), the MPQ (11) and the MPI (12). Individuals agreeing to participate completed the questionnaires and returned them in a prestamped envelope. Two weeks later, subjects were sent a questionnaire 
package consisting of the PBPI, MBQ and BDI. These questionnaires were completed a final time at the clinic visit, approximately four to six months following the initial administration. At all three time points, patients were on a waiting list, awaiting initial assessment. Thus, no treatment was provided at The Rehabilitation Centre during these six months. The final sample comprised 195 subjects (85 males, 109 females, one unidentified).

A diagnosis of chronic pain was made by a multidisciplinary team consisting of a physiatrist, psychologist and physiotherapist following the clinic assessment. All subjects reported pain of at least six months' duration, with a mean duration of 6.3 years ( $\mathrm{SD}=8.25$, range eight months to 50 years). Mean pain intensity was 32.59 ( $\mathrm{SD}=12.89)$ as measured by the MPQ. Approximately $52 \%$ of patients reported lower back pain, $16 \%$ reported pain in the head, face or mouth, $8 \%$ reported cervical pain, $5.6 \%$ reported pain in the extremities and $20.4 \%$ reported pain in other sites (several patients reported pain in multiple sites, resulting in a total greater than $100 \%$ ).

Eight per cent of the sample reported less than eight years of education, $21 \%$ reported nine to 11 years of education, $26 \% \mathrm{com}$ pleted high school, $16 \%$ had 13 to 15 years of education and $12 \%$ had more than 16 years of education. The remainder of the sample did not report level of education. Approximately $14 \%$ of the sample reported an annual family income of less than Cdn $\$ 20,000$, $25 \%$ between $\$ 20,000$ and $\$ 39,999$, and $26 \%$ greater than $\$ 40,000$. The remainder did not report annual family income. Fifteen per cent reported being in a professional or technical position, $20 \%$ were in a managerial or administrative position, $4 \%$ were craftsmen or foremen, $22 \%$ were operatives or in service work, $11 \%$ were manual or farm labourers and $14 \%$ were not in the labour force. The remainder did not report their employment status. Sixty-eight per cent of the sample were Caucasian.

Sample means of skewness and kurtosis for items of the PBPI were -0.97 and 1.43 , respectively, suggesting a relatively normal distribution.

\section{Measures}

BDI: The BDI is a 21-item self-report measure designed to assess depressive symptomatology (17). Beck et al (18) reported an internal consistency estimate of 0.86 , test-retest correlations ranging from 0.48 to 0.86 for varying time intervals, and strong support for construct validity. Turner and Romano (19) demonstrated the applicability of the BDI with chronic pain populations.

MPI: The MPI is a 53-item self-report measure that assesses psychosocial correlates of the pain experience (12). The MPI consists of 13 subscales organized along two axes. The psychosocial axis comprises pain severity, life interference, life control, affective distress and support. The behavioural axis comprises subscales measuring patient's perceptions of spousal use of solicitous responses, punishing responses and distracting responses. Additionally, four subscales measuring activity level (housework, outdoor work, social activity and activity away from home) can be summed to yield a general activity subscale. Adequate reliability and discriminant validity have been demonstrated $(12,20)$.

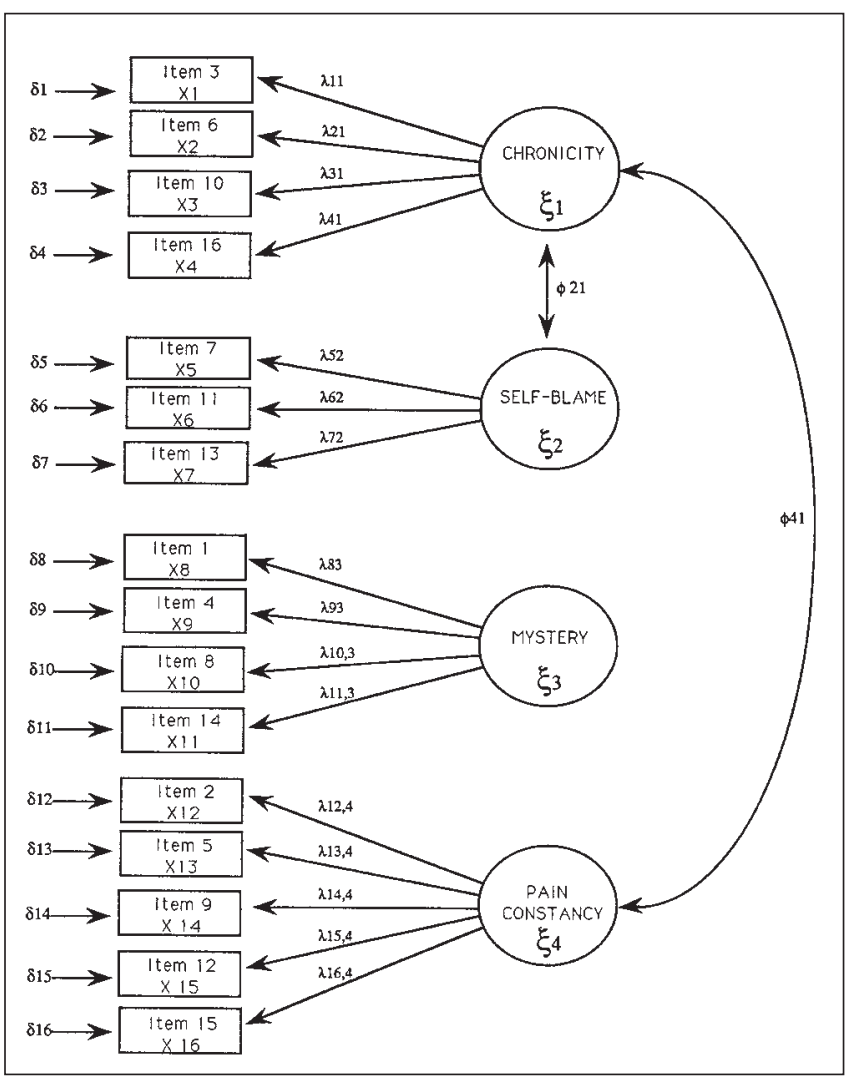

Figure 1) Hypothesized four-factor model of Pain Beliefs and Perceptions Inventory

MPQ: The MPQ comprises 20 groups of adjectives commonly used as descriptors of chronic pain. Factor analytic studies have revealed three main factors (sensory, affective and evaluative pain descriptors) and a miscellaneous factor (11). These subscales can be summed to yield a total pain rating score, which represents an accepted measure of pain severity.

MBQ: The MBQ is a 16-item measure comprising statements describing a variety of blame situations which respondents are asked to rate on a five-point Likert scale ranging from 0 (not at all like me) to 4 (very much like me). The scale has been demonstrated to have good internal consistency $(0.77)$, concurrent validity and construct validity (14) in both normative and psychiatric populations. The questionnaire consists of self-blame and other blame subscales.

\section{Approach to data analysis}

Analyses began with a CFA (LISREL VII, SPSS Inc, Illinois) aimed at testing the hypothesized four-factor solution presented in Figure 1. CFA is considered appropriate in situations where a factor structure has been identified in previous research using exploratory factor analysis.

Previous research has imposed an orthogonal structure on the factors; hence, the extent to which these factors may be correlated is yet to be delineated. Thus, in the initial model, factors were allowed to correlate freely to examine their relatedness. Byrne and colleagues (21) suggest that most psychological constructs have some degree of overlap, and thus, within the context of the initial 
TABLE 1

Correlation matrix for confirmatory factor analysis

\begin{tabular}{|c|c|c|c|c|c|c|c|c|c|c|c|c|c|c|c|c|}
\hline & P1 & P2 & P3 & P4 & P5 & P6 & P7 & P8 & P9 & P10 & P11 & P12 & P13 & P14 & P15 & P16 \\
\hline P1 & 1000 & & & & & & & & & & & & & & & \\
\hline P2 & 731 & 1000 & & & & & & & & & & & & & & \\
\hline P3 & -143 & 078 & 1000 & & & & & & & & & & & & & \\
\hline P4 & 261 & 168 & -111 & 1000 & & & & & & & & & & & & \\
\hline P5 & -022 & 431 & 201 & 223 & 1000 & & & & & & & & & & & \\
\hline P6 & -088 & 166 & 589 & 018 & 434 & 1000 & & & & & & & & & & \\
\hline P7 & -041 & -085 & -181 & 096 & 028 & -146 & 1000 & & & & & & & & & \\
\hline P8 & 246 & 003 & -035 & 218 & 051 & 026 & 078 & 1000 & & & & & & & & \\
\hline P9 & -078 & 314 & 238 & 016 & 413 & 255 & 087 & -029 & 1000 & & & & & & & \\
\hline P10 & 026 & 111 & 331 & 019 & 319 & 509 & -172 & 107 & 138 & 1000 & & & & & & \\
\hline P11 & -004 & -097 & -048 & 032 & 001 & -079 & 618 & -013 & 039 & -139 & 1000 & & & & & \\
\hline P12 & -231 & 164 & 242 & -049 & 424 & 206 & 106 & 011 & 436 & 121 & 065 & 1000 & & & & \\
\hline P13 & -032 & 063 & -084 & 073 & 074 & -063 & 334 & 025 & 102 & -178 & 397 & 182 & 1000 & & & \\
\hline P14 & 413 & 091 & -145 & 328 & -075 & -138 & -021 & 318 & -105 & -069 & -008 & -174 & 045 & 1000 & & \\
\hline P15 & -128 & 230 & 308 & 050 & 498 & 313 & -112 & 087 & 471 & 222 & -067 & 530 & 059 & -121 & 1000 & \\
\hline P16 & -085 & 070 & 328 & 097 & 299 & 459 & -115 & 121 & 132 & 422 & -095 & 052 & -031 & -054 & 134 & 1000 \\
\hline Mean & 0.64 & 1.2 & 0.89 & 0.79 & 1.19 & 1.24 & -1.53 & 0.84 & 0.90 & 1.56 & -1.58 & 0.36 & -1.27 & 0.026 & 0.84 & 1.59 \\
\hline SD & 1.46 & 1.15 & 1.41 & 1.38 & 1.18 & 1.09 & 0.98 & 1.37 & 1.44 & 0.89 & 0.89 & 1.40 & 1.18 & 1.57 & 1.38 & 0.90 \\
\hline
\end{tabular}

\section{TABLE 2}

Summary of respecification steps from null to final model

\begin{tabular}{|c|c|c|c|c|c|c|c|c|c|}
\hline Models & $\chi^{2}$ & df & $\Delta \chi^{2}$ & $\Delta \mathbf{d f}$ & $\chi^{2} / \mathrm{df}$ & GFI & CFI & TLI & PCFI \\
\hline O Null & 843.46 & 120 & & & 7.03 & & & & \\
\hline 1 Initial & 166.55 & 102 & 676.91 & 18 & 1.63 & 0.90 & 0.91 & 0.90 & 0.76 \\
\hline \multicolumn{10}{|c|}{ Parameter added } \\
\hline 2 TD $(13,12)$ & 153.82 & 101 & $12.73^{*}$ & 1 & 1.52 & 0.91 & 0.93 & 0.91 & 0.78 \\
\hline 3 TD $(13,9)$ & 143.21 & 100 & $10.61^{*}$ & 1 & 1.43 & 0.92 & 0.94 & 0.93 & 0.78 \\
\hline $41 \times(13,1)$ & 133.47 & 99 & $9.74 *$ & 1 & 1.35 & 0.92 & 0.95 & 0.94 & 0.79 \\
\hline 5 TD $(13,1)$ & 122.47 & 98 & $11.00^{*}$ & 1 & 1.25 & 0.93 & 0.97 & 0.96 & 0.79 \\
\hline $61 \times(16,2)$ & 115.08 & 97 & $7.39 * *$ & 1 & 1.19 & 0.93 & 0.98 & 0.97 & 0.79 \\
\hline
\end{tabular}

$T D(13,12)$ error correlation between items 2 and $5 .{ }^{*} P<0.001 ;{ }^{*} P<0.01$. df degrees of freedom; CFI Comparison Fit Index (see reference 24); GFI Goodness-of-Fit Index (from Tanaka JS, Huba GL. Confirmatory hierarchial factor analysis of psychological distress measures. I Pers Soc Psychol 1984;46:621-35); PCFI Parsimonious normed Comparative Fit Index (see reference 25); TLI Tucker-Lewis Index (see reference 23)

stages of factor analysis, should be allowed to correlate. Based on the post hoc evaluation of this model (LISREL $t$ values) factors were not allowed to correlate, with the following exceptions: the chronicity and self-blame factors; and the chronicity and pain constancy factors. For the purpose of identification, the first element of each congeneric set was fixed to 1.0.

The next stage of analysis resulted from findings of a less than adequate statistical fit for the data. Although, from a practical perspective, the hypothesized model was satisfactory, a sensitivity analysis was calculated in an exploratory fashion to delineate the cause of the model misfit. All analyses were based on covariance matrices and listwise deletion of data. Means, SDs and the correlation matrix comprising variables used in the analysis are presented in Table 1.

\section{Assessing model fit}

Assessment of fit was based on multiple criteria that reflected statistical, practical and theoretical considerations (21). Good fitting models are regarded as those that pass more tests; hence multiple fit indicators were calculated to satisfy this criterion (22). These 
included the likelihood ratio; Tucker-Lewis Index (23); the Bentler (24) revised normed Comparative Fit Index (CFI); and the Parsimonious Comparative normed Fit Index (PCFI [25]). Identification of sources of misfit within the specified model proceeded in the following manner: examination of the standardized residuals and modification indices (MIs); statistical significance of individual parameters as indicated by the LISREL t values; and their substantive meaningfulness in the model. Upon examination of these indices, a sensitivity analysis was conducted to assess the degree of improvement that each newly specified model presented over its predecessor. Constraints were not relaxed unless it made substantive sense to do so. This procedure generated a final model that reflected the most parsimonious, yet substantively meaningful, best-fitting model to represent the observed data (26). The adequacy of the final model was based on the statistical, practical and, more importantly, the substantive meaningfulness of the solution. The latter criterion was based on the authors' empirical and theoretical knowledge of the subject area.

\section{Confirmatory factor analysis}

\section{RESULTS}

As shown in Table 2, the fit of the hypothesized model was satisfactory from a practical perspective, $\mathrm{CFI}=0.90$; however, it was not acceptable from a statistical perspective, ${ }^{2}(102, \mathrm{n}=195)=$ $166.55, \mathrm{P}<0.001$. Although the coefficient of determination for model 1 was excellent (0.997), indicating that the combination of the 16 items served to measure the factors adequately, the reliability of each item $\left(\mathrm{R}^{2}\right)$ with respect to its underlying latent construct ranged from excellent to poor. Specifically, the most reliable item in model 1 was item 6 (continuously in pain; $\mathrm{R}^{2}=0.76$ ), and item 2 was the least reliable (pain was curable; $\left.\mathrm{R}^{2}=0.18\right)$.

\section{Sensitivity analysis}

As shown in Figure 1, all loadings in model 1 were statistically significant. Given the lack of statistical fit with the observed data, this model was rejected and the analysis proceeded in an exploratory fashion to specify the sources of misfit in the current model and a series of alternative models.

Alternative models were generated by relaxing the constraints for each specified model one at a time, using the MIs as a guide, for those parameters in which it made substantive sense to do so. The final model is presented schematically in Figure 2.

\section{MIs}

The highest MIs encountered represented error covariance between item 5 and item $2\left({ }^{\varsigma} 13,12 ; \mathrm{MI}=12.90\right)$, item 5 and item 4 $\left({ }^{\varsigma} 13,9 ; \mathrm{MI}=10.04\right)$, and item 5 and item $3\left({ }^{\varsigma} 13,1 ; \mathrm{MI}=6.77\right)$; and a secondary loading between item 5 and chronicity $\left({ }^{\lambda} 13,1 ; \mathrm{MI}=\right.$ 9.87), and item 15 and self-blame $\left({ }^{\lambda} 16,2 ; \mathrm{MI}=6.77\right)$.

To assess the extent to which each newly specified model represents an improvement over the previous model, the difference in ${ }^{2}$ between the two models ( ${ }^{2}$ ) were examined (26). This differential is itself ${ }^{2}$ distributed, with degrees of freedom equal to the difference in degrees of freedom between the two models ( 2 ) value.

Reviewing the results related to models 2, 3, 4, 5 and 6 (Table

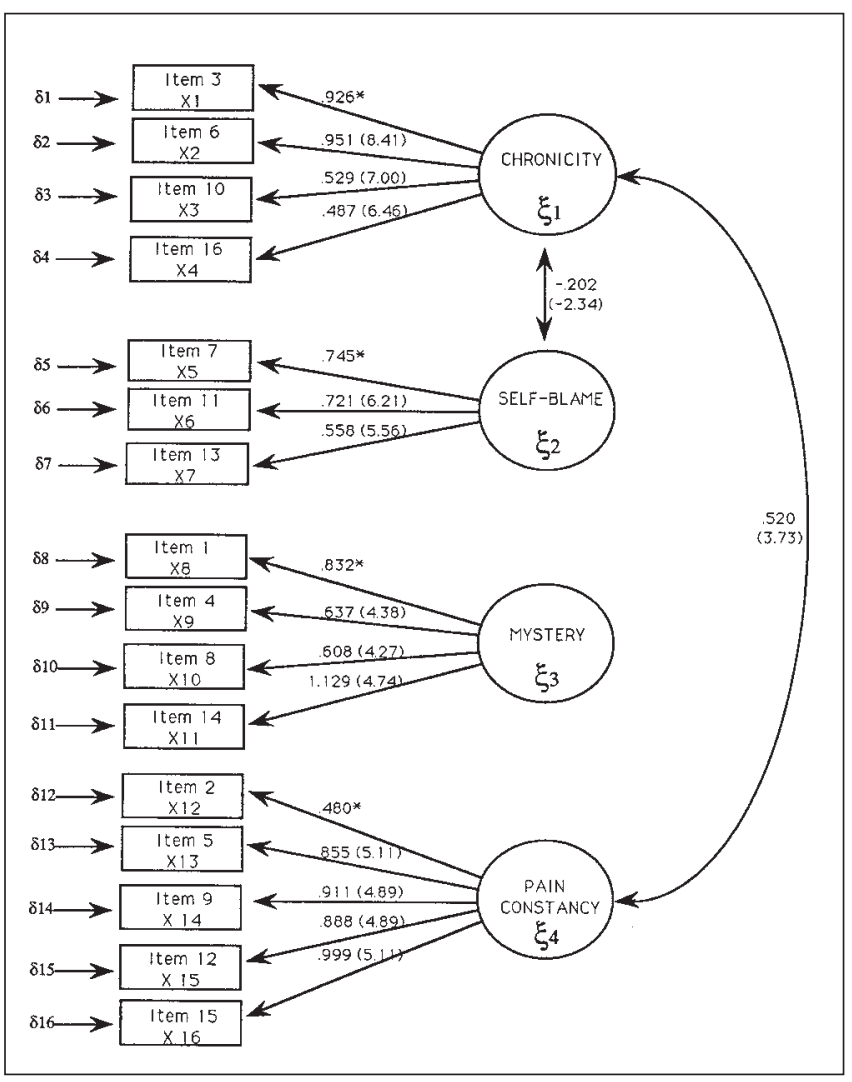

Figure 2) Standardized estimates for four-factor structure (initial model) underlying 16-item Pain Beliefs and Perceptions Inventory on a sample of 195 chronic pain patients. Parenthesized values represent $t$ values of parameter estimates; values $>2.00$ indicate statistical significance $(\mathrm{P}<0.05)$. Values in boxes represent scale numbers. *Parameter fixed to 1.0 for purposes of statistical identification

2), the estimation of each yielded a significant improvement in fit over its predecessor. Specifically, each error covariance, when relaxed, resulted in a statistically significant ${ }^{2}$. This also was the case when the two cross-loadings were input into the model. Model 6 resulted in a statistically better fit than the initial model,

${ }^{2}(97, n=195)=115.08, P=0.102$. However, based on the following considerations, these respecified models were rejected in favour of the more parsimonious initial model. One way of identifying an overfitted model is to test the sensitivity of major parameters in the model to the addition of the post hoc parameters (26). This can be estimated by correlating major parameters (estimated factor loadings and estimated variance/covariances) in the initial model with those of the best-fitting post hoc model. Correlation coefficients that are not close to 1.00 (eg, <0.90) indicate that the major parameters are adversely affected. This information must also be balanced by the substantive meaningfulness of the model relative to the theory and other empirical research. Applied to the present data, the preceding analyses yielded the following results: the correlation between the estimated factor loadings of the initial and final models was 0.960 ; the correlation between the estimated variance/covariances of the initial and final models was 0.999 . The PCFI remained relatively unchanged throughout the model respecifications, indicating that the post hoc models did not represent a substantive improvement over the 
TABLE 3

Reliabilities for the subscales of the Pain Beliefs and Perceptions Inventory

\begin{tabular}{lccc}
\hline Subscale & $\begin{array}{c}\text { Test-retest at } \\
\text { 2 weeks }\end{array}$ & $\begin{array}{c}\text { Test-retest at } \\
\text { 4 to } 6 \text { months }\end{array}$ & $\begin{array}{c}\text { Internal con- } \\
\text { sistency }\end{array}$ \\
\hline Self-blame & $0.49(n=168)$ & $0.58(n=48)$ & $0.70(n=195)$ \\
Pain constancy & $0.67(n=166)$ & $0.59(n=50)$ & $0.75(n=195)$ \\
$\begin{array}{c}\text { Understanding of } \\
\text { chronicity }\end{array}$ & $0.67(n=149)$ & $0.59(n=45)$ & $0.76(n=195)$ \\
Mystery & $0.56(n=161)$ & $0.43(n=48)$ & $0.63(n=195)$ \\
\hline
\end{tabular}

Unequal $n$ 's are due to incomplete data sets and 'spoiled' responses

original hypothesized model. These results substantiate the stability of the initial model (26).

As noted by Byrne (26), the presentation of these artefacts is reasonable when analyses are focused on a single measuring instrument. Although each of the relatively small model respecifications yielded a statistically significant improvement in model fit, the increments based on goodness-of-fit indices, which were already acceptable in the initial model, could be considered of little practical importance $(26,27)$. Furthermore, the sensitivity of the ${ }^{2}$ likelihood ratio test with large samples is widely known $(27,28)$. Given the exploratory nature of the post hoc analyses, and the associated risk of capitalization on change factors (29), the final model estimates were considered to be less than robust and, therefore, would be difficult to replicate. For these reasons, the post hoc model was rejected in favour of the more parsimonious initial hypothesized model (model 1) as presented in Figure 2.

\section{Psychometric properties of the PBPI}

Test-retest reliabilities over a two- to four-week period ranged from 0.49 to 0.68 , and 0.43 to 0.59 over a four- to six-month interval. As can be seen from Table 3 , there was a substantial decrease in number of respondents from time 2 to time 3 . To determine the extent to which subjects completing the questionnaire at all three time points are representative of the initial sample, a series of one-way ANOVAs were conducted comparing the samples of respondents completing the PBPI at all three time points; time 1 and 2 ; and time 1 only. Dependent measures were the total pain beliefs score and the four subscale scores of the PBPI. No significant differences were found. Total scale and subscale means, SDs and ranges also appeared to be comparable, suggesting that attrition at time 3 was unrelated to subjects' pain beliefs, and that the results are generalizable (Table 4).

Internal consistency of the subscales ranged from 0.63 (MYST) to 0.76 (understanding of chronicity). These values are somewhat lower than those reported by Morley and Wilkinson (9), which ranged from 0.80 (pain persistency, ie, understanding of chronicity) to 0.89 (self-blame).

Construct validity of the factors was further established by examining the pattern of correlations between factor scores and the various criterion measures specified. Factor scores were calculated for each subject by summing items on each of the factors.

\begin{tabular}{|c|c|c|c|c|c|}
\hline Scale & Time & Mean \pm SD & Range & $\mathbf{F}$ & p \\
\hline \multirow[t]{3}{*}{ Total } & 1 & $7.12 \pm 7.79$ & $-16.00 \pm 23.00$ & & \\
\hline & 2 & $5.68 \pm 8.48$ & $-25.00 \pm 28.00$ & & \\
\hline & 3 & $6.30 \pm 9.41$ & $-18.00 \pm 26.00$ & 2.19 & 0.12 \\
\hline \multirow[t]{3}{*}{ Self-blame } & 1 & $-4.44 \pm 2.38$ & $-6.00 \pm 6.00$ & & \\
\hline & 2 & $-4.22 \pm 2.46$ & $-6.00 \pm 6.00$ & & \\
\hline & 3 & $-3.33 \pm 2.99$ & $-6.00 \pm 6.00$ & 1.47 & 0.24 \\
\hline Pain & 1 & $5.37 \pm 3.20$ & $-8.00 \pm 9.00$ & & \\
\hline \multirow[t]{2}{*}{ Constancy } & 2 & $4.59 \pm 3.58$ & $-8.00 \pm 8.00$ & & \\
\hline & 3 & $4.48 \pm 3.33$ & $-6.00 \pm 8.00$ & 0.64 & 0.53 \\
\hline Understand & 1 & $4.36 \pm 4.77$ & $-10.00 \pm 10.00$ & & \\
\hline \multirow[t]{2}{*}{ Chronicity } & 2 & $3.83 \pm 4.82$ & $-10.00 \pm 10.00$ & & \\
\hline & 3 & $3.91 \pm 4.69$ & $-9.00 \pm 10.00$ & 0.91 & 0.41 \\
\hline \multirow[t]{3}{*}{ Mystery } & 1 & $2.13 \pm 4.08$ & $-8.00 \pm 8.00$ & & \\
\hline & 2 & $1.48 \pm 4.07$ & $-8.00 \pm 8.00$ & & \\
\hline & 3 & $1.19 \pm 3.83$ & $-8.00 \pm 8.00$ & 2.23 & 0.11 \\
\hline
\end{tabular}

Self-blame scores achieved moderately positive correlations with the Bulman-Wortman rating of general blame, weak positive correlations with the MBQ self-blame subscale and the Bulman Wortman self-blame scale, and was uncorrelated with the MBQ other blame scale (Table 5).

Pain constancy scores achieved moderate positive correlations with general ratings of present, most and least severe pain, and weak positive correlations with the MPI pain severity scale and the MPQ total score (Table 5).

Understanding of chronicity scores achieved weak positive correlations with the general ratings of pain as well as the MPQ total score and the MPI pain severity scale (Table 5).

Finally, the MYST subscale achieved weak negative correlations with the BDI, happiness and dissatisfaction ratings. As such, the meaning of the construct reflected by this subscale has not been clearly defined.

\section{DISCUSSION}

Results of this study support recent work indicating that the PBPI comprises four factors (7-9). Initially, Williams and Thorn (1) proposed a three-factor model consisting of TIME, MYST and $\mathrm{S}-\mathrm{B}$ subscales. The latter two dimensions were replicated with no alteration in item content. However, in the current investigation the time dimension split into two correlated factors: understanding of chronicity and pain constancy.

Further evidence for the construct validity of the four factors was obtained by examining the relationship between subjects' scores on each factor and several standardized measures of related constructs. Generally, the results were consistent with the original work of Williams and Thorn (1). However, nonsignificant correlations were obtained between the mystery factor and 
TABLE 5

Relationship between criterion measures and subscales of the Pain Beliefs and Perceptions Inventory

\begin{tabular}{|c|c|c|c|c|c|c|c|c|c|}
\hline Factor & & \multicolumn{2}{|c|}{ MPI pain } & \multicolumn{2}{|c|}{ MPQ total } & Present pain & \multicolumn{2}{|c|}{ Most pain } & Least pain \\
\hline \multicolumn{2}{|c|}{ Pain constancy } & \multicolumn{2}{|c|}{$0.29 * * *$} & \multicolumn{2}{|c|}{$0.27^{* *}$} & $0.51 * * *$ & \multicolumn{2}{|c|}{$0.41 * * *$} & $0.42 * * *$ \\
\hline \multicolumn{2}{|c|}{ Understanding of chronicity } & \multicolumn{2}{|c|}{$0.12 *$} & \multicolumn{2}{|c|}{$0.20^{*}$} & $0.23 * * *$ & $0.22^{* *}$ & \multicolumn{2}{|c|}{$0.15^{*}$} \\
\hline & Happiness rating $\mathrm{Ge}$ & neral activi & ity $\mathrm{Ho}$ & tousehold chores & Outdoor work & k Activities & out of home & Social activities & BDI \\
\hline \multirow[t]{2}{*}{ Mystery } & $-0.13^{*}$ & ns & & ns & ns & & ns & ns & $0.15^{*}$ \\
\hline & MPI pain severity & MSB & МОВ & B General blame & Self-blame & $\begin{array}{l}\text { Other } \\
\text { blame }\end{array}$ & Chance blame & Avoidance rating & BDI \\
\hline Self-blame & $-0.12 *$ & $0.29 * * *$ & $\mathrm{~ns}$ & $0.52 * * *$ & $0.20^{* *}$ & $-0.13 * *$ & $-0.25 * *$ & $0.13 *$ & $0.12 *$ \\
\hline
\end{tabular}

measures of activity level. Williams and Thorn (1) measured activity level indirectly by obtaining clinicians' ratings of treatment adherence, reasoning that uncertainty about the nature of one's pain may result in anxiety that would lead individuals to avoid activity. The present results suggest that beliefs that one's pain is mysterious are modestly correlated with mood. The MYST subscale achieved a modest positive correlation with the BDI and a negative correlation with ratings of happiness. This finding is consistent with the hypothesis that this aspect of pain beliefs is associated with negative affectivity. However, these results did not support the hypothesis that beliefs that one's pain is mysterious and unexplained results in an avoidance of activity, at least not when activity level is measured through self-report. What may be tentatively concluded, based on these results and those of Williams and Thorn (1), is that patients who have a clear understanding of their pain are more compliant with treatment recommendations. If this relationship can be substantiated prospectively it would represent an important use of the PBPI in pretreatment screening. However, it should be noted the MYST subscale demonstrated the lowest internal consistency and relatively low testretest reliability. Thus, further refinement of this subscale and the construct may be necessary before it can be used clinically.

The S-B subscale demonstrated reasonable internal consistency. Test-retest reliability was low at two weeks, but acceptable at the four- to six-month interval. The pattern of correlations between the $\mathrm{S}-\mathrm{B}$ subscale and the various blame measures suggest that S-B may be more of a measure of general blame versus a specific measure of self-blame. This is an important distinction, which helps to explain the low correlation between the S-B subscale and the BDI. Previous research has demonstrated a strong association between self-blame and depression (14). The absence of such a relationship in the present investigation suggests that the S-B subscale may be measuring additional constructs, such as anger, hostility or, more generally, negative affectivity. Negative affectivity has been found to be significantly correlated with measures of self-reported health as rated by individuals with rheumatoid arthritis (30), and may have applicability to our understanding of adjustment to chronic pain in general. Overall, however, the nature of the construct being tapped by the S-B scale and its clinical utility require further empirical investigation.

Results revealed modest test-retest reliability for the pain constancy and understanding of chronicity factors, and acceptable internal consistency estimates for these subscales. Test-retest reliability for the mystery and self-blame factors is considered unacceptable for constructs that would generally be considered stable aspects of an individual's belief system. Anastasi (31) suggests that, for clinical purposes, acceptable levels of reliability are 0.80 or greater. Reliability levels less than 0.60 are considered unacceptable. The instability of the mystery and self-blame factors may be due to one or more of the following: the small number of items comprising the factors; the wording of the items; and the potential for situational variability to have an impact on the responses to items within these factors.

Given that these factors have few items, small inconsistencies in an individual's response over time will have a greater impact than factors comprising many items. While the psychometric properties of the PBPI might be improved if the number of items were increased, the small number of items cannot adequately account for the low reliability of the mystery and self-blame factors, given that the constancy and understanding of chronicity factors have comparably few items yet exhibit higher test-retest reliabilities.

The wording of the items comprising the mystery and self-blame factors may result in different interpretations of the questions both between individuals and within an individual over time, and consequently may contribute to their instability. The majority of the items can be interpreted as addressing either the initial cause and onset of the pain problem, or current fluctuations in pain intensity. For example, items such as "If I am in pain it is my own fault", "I am the cause of my pain" or "I can't figure out why I' $m$ in pain" can be interpreted as referring to the event that initiated the pain problem or, alternatively, to the current pain or a recent flare-up. Individuals may not interpret the item in the same manner between testing sessions. That is, individuals may interpret the items as referring to the initial cause of their pain on one occasion and then interpret the question as a belief about the pain they are currently experiencing on the next occasion. 
Finally, if the mystery and self-blame factors are interpreted with regards to the etiology of pain, it is likely that these beliefs are affected by the individual's current situation and knowledge, and, as such, are likely to be as variable over time as beliefs regarding current fluctuations in pain experience. Such changes in beliefs would contribute to low test-retest reliability. If this hypothesis is accurate, understanding the situational variables that lead to changes in beliefs would advance efforts to design treatment interventions for varying subgroups of pain patients, as well as would identify the optimal timing of particular interventions over the course of treatment. The apparent fluidity of these dimensions may indicate that these subscales may be sensitive to process issues and capable of reflecting changes in belief systems in response to treatment intervention.

These results suggest that further understanding and refinement of the MYST and S-B subscales are required if the PBPI is to be used to identify treatment objectives and assess treatment outcome. The use of a repeated-measures methodology over brief time intervals may prove particularly valuable in fostering our understanding of these two components of the PBPI.

ACKNOWLEDGEMENTS: This research was supported by a grant of the Labatt's Blue Light Relay Fund. The authors extend their gratitude to Susan DuBreuil for assistance in the preparation of the initial grant proposal, to Joanne Licari and Teressa Sasseville for assistance in data management, and to members of The Rehabilitation Centre's Pain Clinic for assessments of the patients. We also thank Dr Keith Wilson and the three reviewers for their helpful suggestions regarding the manuscript, our occasional failures of logic and their kind comments.

\section{REFERENCES}

1. Williams DA, Thorn BE. An empirical assessment of pain beliefs. Pain 1989;36:351-8.

2. Gottlieb BS. Predicting outcome in pain programs: A matter of cognition. Paper presented at the American Psychological Association Annual Convention, Washington DC, 1986.

3. Gottlieb BS. Development of the pain beliefs questionnaire: A preliminary report. Paper present at the Association for the Advancement of Behaviour Therapy, Philadelphia, 1984.

4. Jensen MP, Karoly P. Control beliefs, coping efforts and adjustment to chronic pain. J Consult Clin Psychol 1991;59:431-8.

5. Jensen MP, Karoly P. Pain-specific beliefs, perceived symptom severity, and adjustment to chronic pain. Clin J Pain 1992;8:123-30.

6. Jensen MP, Turner JA, Romano JM, Lawler BK. Relationship of pain specific beliefs to chronic pain adjustment. Pain 1994;57:301-10.

7. Herda CA, Siegeris K, Basler H-D. The Pain Beliefs and Perceptions Inventory: further evidence for a 4-factor structure. Pain 1994;57:85-90

8. Strong J, Ashton R, Chant D. The measurement of attitudes towards and beliefs about pain. Pain 1992;48:227-36.

9. Morley S, Wilkinson L. The pain beliefs and perceptions inventory: a British replication. Pain 1995;61:427-33.

10. Gorsuch RL. Factor Analysis, 2nd edn. New Jersey: Lawrence Erlbaum Associates, 1983.

11. Melzack R. The McGill Pain Questionnaire: major properties and scoring methods. Pain 1975;1:277-99.

12. Kerns RD, Turk DC, Rudy TE. The West Haven-Yale Multidimensional Pain Inventory (WHYMPI). Pain 1985;23:345-56.

13. Bulman RJ, Wortman CB. Attributions of blame and coping in the 'real world': Severe accident victims react to their lot. J Pers Soc Psychol 1977;35:351-63.

14. Mittelstaedt WR. Development and validation of a measure of self and other: Blaming personality tendencies. Doctoral dissertation.

University of Saskatchewan, 1989.

15. Mikail SF, DuBreuil S, D'Eon JL. A comparative analysis of measures used in the assessment of chronic pain patients. Psychol Assess: J Consult Clin Psychol 1993;5:117-20.

16. De Gagné TA, Mikail SF, D’Eon JL. Confirmatory factor analysis of a four-factor model of chronic pain evaluation. Pain 1995;60:195-202.

17. Beck AT, Ward CH, Mendelson M, Moch J, Erbaugh J. An inventory for measuring depression. Arch Gen Psychiatr 1961;4:561-71.

18. Beck AT, Steer RA, Garbin MG. Psychometric properties of the Beck Depression Inventory: Twenty five years of evaluation. Clin Psychol Rev 1988;8:77-100.

19. Turner JA, Romano JM. Self-report screening measures for depression in chronic pain patients. J Consult Clin Psychol 1984;40:909-13.

20. Turk DC, Rudy TE. The robustness of an empirically derived taxonomy of chronic pain patients. Pain 1990;43:27-35.

21. Byrne BM, Shavelson RJ, Muthén B. Testing for the equivalence of factor covariance and mean structures: The issue of partial measurement invariance. Psychol Bull 1989;105:456-66.

22. Carlson M, Mulaik SA. Trait ratings from descriptions of behavior as mediated by components of meaning. Multivariate Behav Res 1993;28:111-59.

23. Tucker LR, Lewis C. A reliability coefficient for maximum likelihood factor analysis. Psychometrika 1973;38:1-10.

24. Bentler PM. Comparative fit indexes in structural models. Psychol Bull 1990;107:238-46.

25. Mulaik SA, James LR, Van Alstine J, Bennett N, Stillwell CD. An evaluation of goodness of fit indices for structural equation models. Psychol Bull 1989;105:430-45.

26. Byrne BM. A Primer of LISREL: Basic Applications and Programming for Confirmatory Factor Analytic Models. New York: Springer-Verlag, 1989.

27. Marsh HW, Hocevar D. Application of confirmatory factor analysis to the study of self-concept: First- and higher order factor models and their invariance across groups. Psychol Bull 1985;97:562-82.

28. Bentler PM, Bonett DG. Significance tests and goodness of fit in the analysis of covariance structures. Psychol Bull 1980;88:588-606.

29. MacCallum R. Specification searches in covariance structure modelling. Psychol Bull 1986;100:107-20.

30. Smith CA, Wallston KA, Dwyer KA. On babies and bathwater: disease impact and negative affectivity in the self-reports of persons with rheumatoid arthritis. Health Psychol 1995;14:164-73.

31. Anastasi A. Psychological Testing, 6th edn. New York: Macmillan, 1988. 


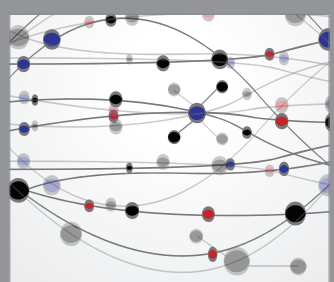

The Scientific World Journal
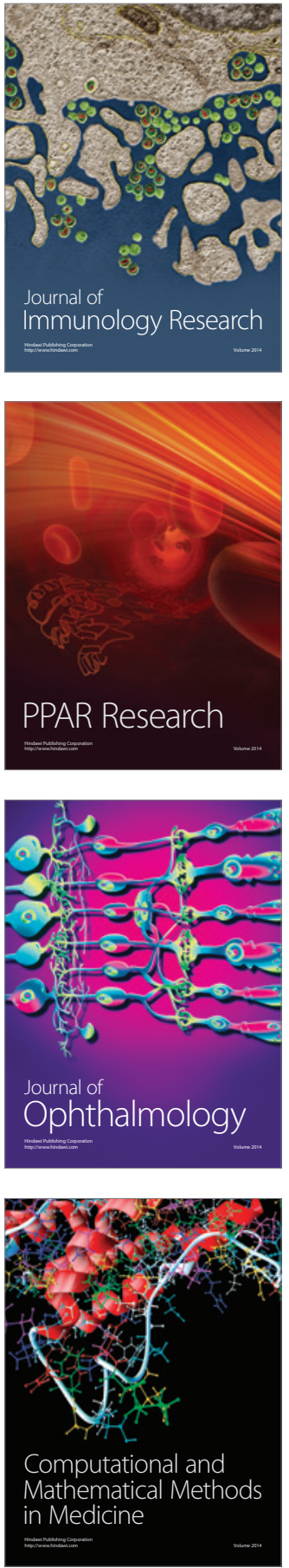

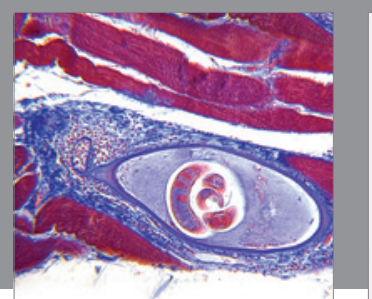

Gastroenterology Research and Practice

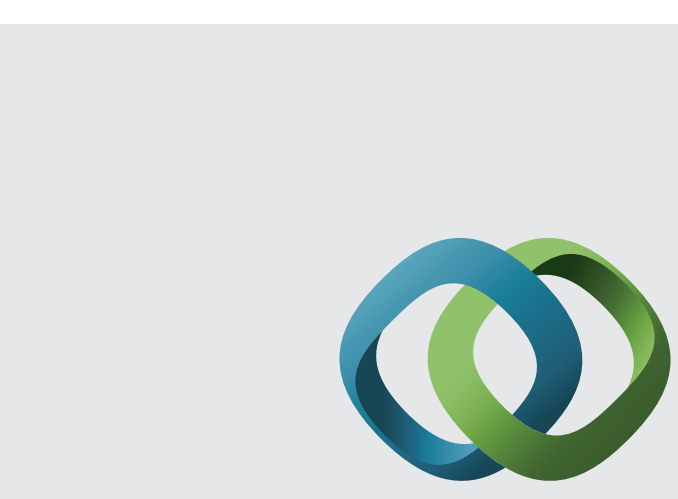

\section{Hindawi}

Submit your manuscripts at

http://www.hindawi.com
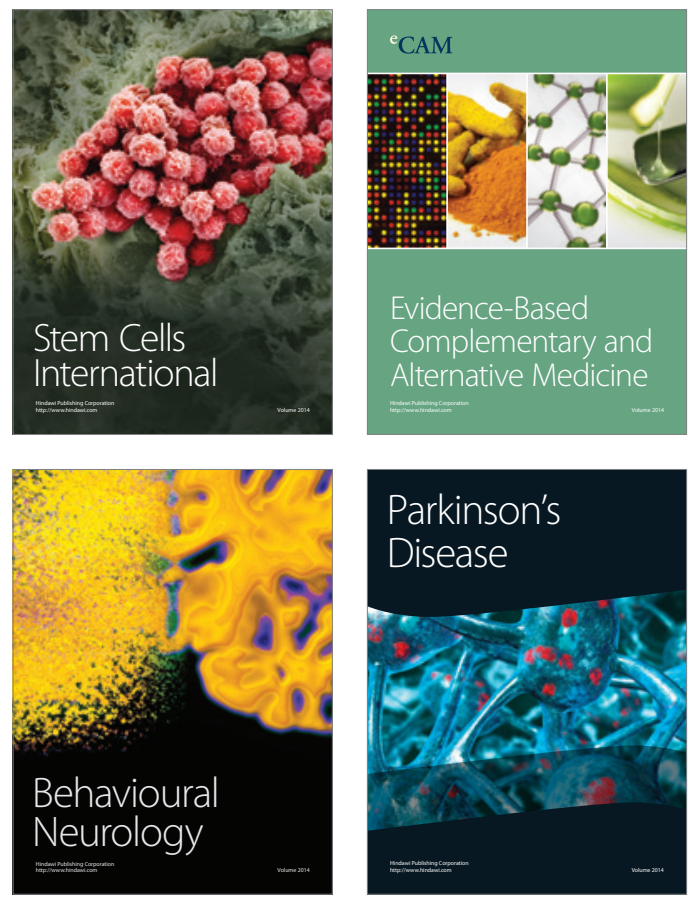
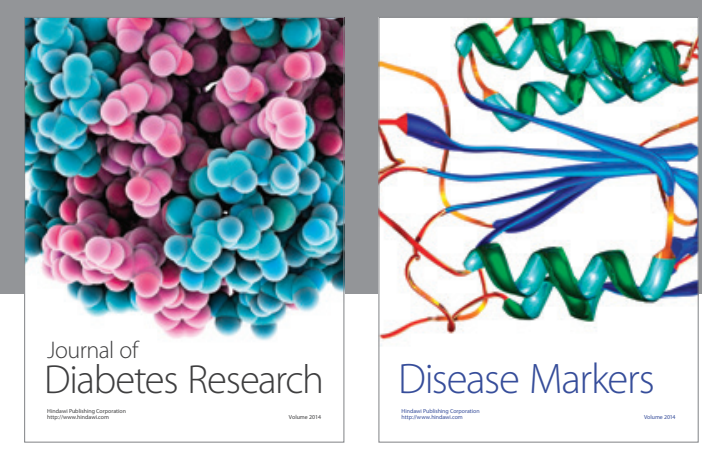

Disease Markers
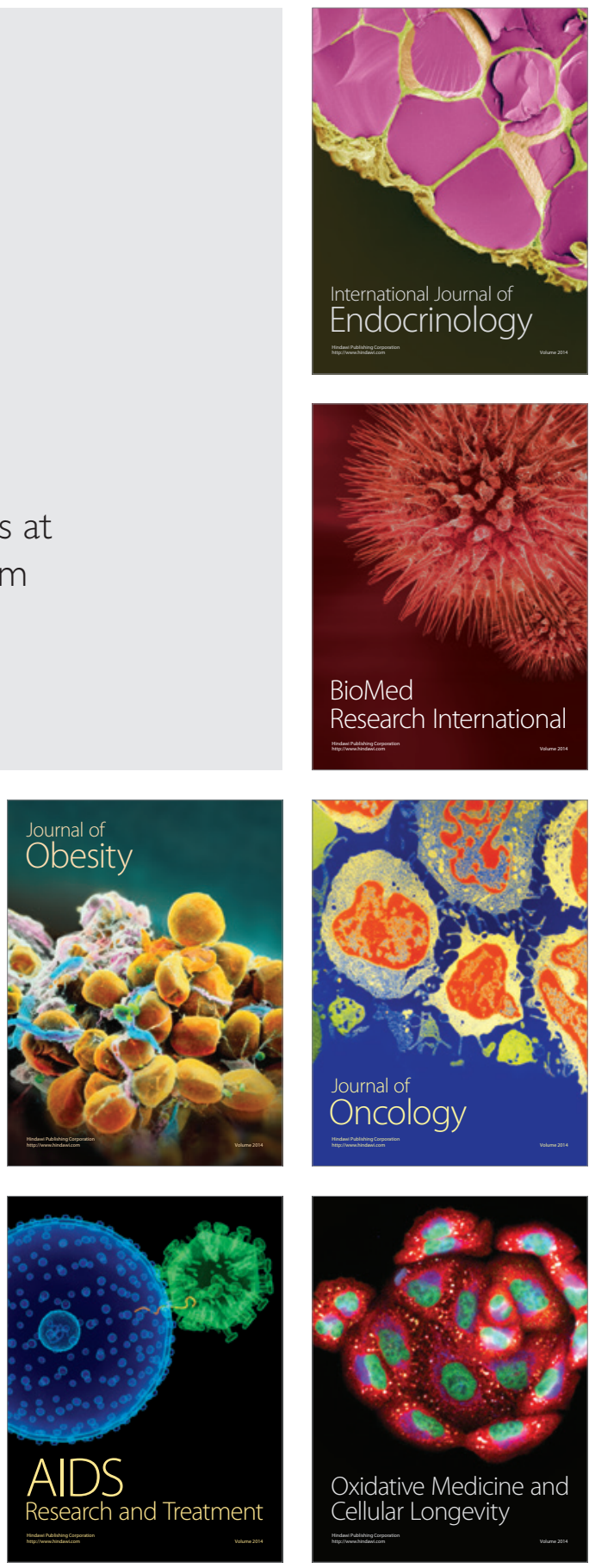